\title{
Configurações
}

Revista de sociologia

\section{Etnografias da prisão: novas direções}

New Directions in Prison Ethnography

Ethnographie de la Prison: nouvelles directions

\section{Manuela Ivone Cunha}

\section{(2) OpenEdition}

\section{Journals}

Edição electrónica

URL: http://journals.openedition.org/configuracoes/2389

DOI: $10.4000 /$ configuracoes.2389

ISSN: 2182-7419

\section{Editora}

Centro de Investigação em Ciências Sociais

\section{Edição impressa}

Data de publição: 30 Junho 2014

Paginação: 47-68

ISBN: 1646-5075

ISSN: 1646-5075

Refêrencia eletrónica

Manuela Ivone Cunha, « Etnografias da prisão: novas direções », Configurações [Online], 13 | 2014 posto online no dia 22 abril 2015, consultado o 30 abril 2019. URL : http://journals.openedition.org/ configuracoes/2389; DOI : 10.4000/configuracoes.2389

Este documento foi criado de forma automática no dia 30 Abril 2019.

(c) CICS 


\title{
Etnografias da prisão: novas direções
}

\author{
New Directions in Prison Ethnography \\ Ethnographie de la Prison: nouvelles directions
}

Manuela Ivone Cunha

\section{Introdução}

1 O que se segue é uma tentativa de traçar o panorama atual da investigação de terreno em torno da prisão e da reclusão penal. São identificadas as principais linhas de evolução contemporânea e caracterizados alguns desenvolvimentos em relação aos debates teórico-metodológicos que dominaram as abordagens clássicas do mundo prisional ${ }^{1}$. Em linha com outras contribuições (e.g., Wacquant 2002), procura-se não confinar este panorama a terrenos anglo-americanos. Quanto aos EUA, é antes de mais uma questão de necessidade, dado o declínio que aí conheceram os estudos no terreno - embora com sinais recentes de retoma -, em contraste com a situação na Europa e na América Latina, onde a vitalidade da tradição destes estudos se manteve. Em segundo lugar, e sobretudo, trata-se de uma opção deliberada para evitar os riscos de um paroquialismo invertido mas não menos equivocado: aquele que toma por universal a produção de centros hegemónicos, esquecendo que também ela reflete particularidades dos contextos societais de onde emana e ignora toda a investigação fora deles por muito relevante e inovadora que seja, agravando assim os efeitos de distorção induzidos pelos desequilíbrios na geopolítica da ciência e na economia simbólica global (Bourdieu e Wacquant, 2002; Ribeiro e Escobar, 2006). Por fim, pretende-se assegurar a diversidade da paisagem comparativa, contemplando a própria diversidade de sistemas prisionais e contextos culturais (e.g., Dores, 2003; King, 2007; Ruggiero et al., 1996).

2 Um enfoque em investigações de terreno não implica divórcio algum entre abordagens micro e macro. Pelo contrário, uma tal oposição não faria jus à maior parte da investigação etnográfica contemporânea em torno da prisão. É uma pesquisa que combina diferentes escalas de análise e inclui formas de poder, governabilidade e transformações 
sociais e culturais mais vastas. Por seu turno, a observação próxima de aspetos intraprisionais contribui para iluminar processos externos. Em coerência com essa perspetiva ampla adotada pelas atuais abordagens de terreno, o mapeamento que aqui se propõe não deixará, pois, de referir, sempre que pertinente, trabalhos históricos, penológicos e outros no âmbito da reclusão e sociedade.

3 Estruturei este percurso em torno de uma questão que permite, por um lado, agregar uma grande variedade de estudos clássicos e contemporâneos numa visão de conjunto coerente e, por outro, destacar inflexões importantes no tipo de temas e perspetivas predominantes ao longo do tempo. Usarei como mote a ligação prisão-sociedade e a articulação entre o mundo interno e externo da prisão. Esta articulação é focada de várias maneiras, ora mais centrada na instituição e no seu funcionamento, nos atores e práticas institucionais (ver primeira secção), ora nos/as prisioneiros/as e no seu mundo social, dentro e fora da prisão (ver segunda e terceira secções). Será óbvio que estes são enfoques descritivo-etnográficos, a não confundir com um qualquer "carcero-centrismo" ideológico alinhado com a instituição prisional (Chantraine, 2013).

4 O termo "prisão" e o corpo principal de referências bibliográficas aqui mencionadas dizem sobretudo respeito a estabelecimentos de média e alta segurança. Outro tipo de detenção, ou tipologias especiais como a "segurança máxima" e as "prisões terapêuticas", tem especificidades que exigiriam um tratamento particular (e.g., Irwin, 1985; Rhodes, 2004; Genders e Players, 2010).

\section{0 carácter situado da investigação prisional de terreno}

5 Antes de focar o conteúdo e a evolução dos temas-chave da investigação prisional de terreno, é importante referir a questão do carácter socialmente situado desta investigação e identificar os tipos e níveis de reflexividade implicados nela.

6 Numa linha paralela, merecem também atenção as condições políticas e práticas de produção de investigação de terreno na prisão. Consoante as entidades financiadoras, o próprio desenho da investigação pode ser predeterminado por agendas mais instrumentais, orientadas diretamente para a produção de políticas, ou ser mais autonomamente motivado por preocupações de cariz teórico.

7 Num meio fechado e coercivo, a questão do acesso ao terreno é decisiva para a viabilidade de investigação etnográfica em profundidade, que por definição inclui não só narrativas suscitadas e entrevistas agendadas, mas também dados não solicitados, produzidos acidentalmente a partir da observação direta e de interações informais e não estruturadas. "Quase-etnografia" é uma expressão justificada, dado ser raro no panorama internacional o acesso sem filtros ou barreiras de investigadores de terreno a estabelecimentos prisionais (Rhodes, 2001; Wacquant, 2002; Waldram, 2009). Existe, ainda assim, um conjunto não negligenciável de etnografias contemporâneas, sobretudo em prisões europeias, que beneficiaram de acesso total, irrestrito e incondicional a instalações prisionais e a prisioneiros/as (e.g., Rowe, 2011; Crewe, 2009; Cunha, 2002, 2008; Ugevik, 2012).

8 Além da exploração específica de vias etnográficas e de técnicas qualitativas em meio carceral, como entrevistas (e.g., Davies, 2000; Jenness, 2010; Sutton, 2011), histórias de vida, autonarrativas e autoetnografi a (Crewe e Maruna, 2006; Jewkes, 2012), a 
investigação de terreno em prisões debruçou-se reflexivamente sobre o seu carácter "situado". Etnógrafos/as prisionais problematizaram a sua própria localização social em termos de etnicidade, género, classe e idade (Phillips e Earle, 2010); o papel assumido ou encoberto como investigador/a (Cohen e Taylor, 1972); a posição real ou imputada de recluso/a (Kaminski, 2004; Spedding, 1999)2, guarda (Fleisher, 1989, Marquart, 1986), visitante (Biondi, 2010), estudante, técnico/a social (Le Caisne, 2000) e outras formas de gestão da identidade nestes contextos (King e Wincup, 2000).

Esta consciencialização explícita inclui também a relação dos etnógrafos/as com os seus interlocutores, o envolvimento emocional e intelectual, a proximidade e o distanciamento, bem como a navegação entre diferentes grupos e estruturas de poder (Cunha, 2002; Liebling, 2001; Nielson, 2010; Sparks, 2002; Sloan e Drake, 2013; King e Wincup, 2000). Longe de meramente confessionais, estes aspetos são passíveis de serem integrados sociologicamente no próprio processo de compreensão das dinâmicas do contexto carceral em estudo (Rhodes, 2001). Mesmo a muito comentada posição do/a etnógrafo/a prisional como outsider, não impede a sua incorporação nestas dinâmicas e pode contribuir igualmente para as revelar, quer esta exterioridade dificulte quer facilite o entabulamento de relações - ou ambas as coisas, em diferentes momentos e circunstâncias (Cunha, 1994, 2002).

10 A consciência da historicidade e contexto cultural de uma dada investigação etnográfica leva, porém, a reflexividade a um outro nível. Permite uma articulação mais situada e sistemática entre aspetos individuais, intersubjetivos, sociais e institucionais, num pano de fundo comparativo face ao qual suposições avulsas na base de um ou outro destes aspetos podem ser testadas de maneira integrada. Revisitações etnográficas de um mesmo terreno prisional - combinadas ou não com comparações interinstituições (e.g., Cunha, 2002; Genders e Players, 2010; Kruttschnitt e Gartner, 2005; Liebling, 2013) - captam a mudança e seus rumos, mas a contextualização temporal também permite uma identificação mais exata das propriedades específicas das diferentes situações carcerais estudadas, bem como da natureza dos fatores que as configuram. Etnografias prisionais conduzidas noutros contextos culturais que não os anglo-americanos, onde se produziu o enquadramento dominante dos estudos prisionais, mostram como diferentes variedades culturais da reclusão se podem combinar com formas globalizadas de poder penal. Contribuem, além disso, para uma compreensão comparativa da fusão entre aspetos inerentes ao meio prisional e aspetos próprios dos diferentes meios culturais do universo carceral (Bandyopadhyay, 2010; Bandyopadhyay, Jefferson e Ugelvik, 2013; Garces, Martin e Darke, 2013; Piacentini, 2004, 2007; Reed, 2004). Numa linha conexa, uma paisagem mais diversificada da etnografia prisional pode afinar uma reflexividade em termos das categorias usadas na análise etnográfica. A raça/etnicidade, para mencionar uma das categorias, é um constructo cultural - e classificação administrativa - altamente variável que não é transponível sem precaução, por exemplo, de contextos norte-americanos para contextos pós-coloniais latino-americanos ou ibéricos ${ }^{3}$. Examinando os significados contextuais de raça/etnicidade como categoria de identidade e organização social numa prisão portuguesa, Cunha $(2002,2010)$ notou a este propósito que esta categoria tinha contornos específicos e não podia simplesmente ser descrita em termos da sua menor saliência quando comparada a prisões nos EUA. No meio extraprisional também era diferentemente configurada por um jogo específico com a classe social, mediado por condições tais como o bairro de residência e a organização específica da economia retalhista da droga em Portugal. Outras etnografias em prisões europeias também 
mostraram como o local de proveniência, o background cultural, a religião e a comunidade de vivências se sobrepõem à raça/etnicidade na vida social da prisão, mesmo quando aparentam coincidir com alinhamentos etnorraciais (Crewe, 2009; Genders e Players, 1989; Khosrokhavar, 2004; Phillips e Earle, 2010).

11 As abordagens de terreno da prisão têm refletido debates teóricos gerais sobre etnicidade/raça, classe, género, bem como as interseções entre eles. O género, porém, informou os estudos prisionais de maneira diversa consoante estes incidissem sobre prisões masculinas ou femininas. No caso das masculinas, a investigação deixou de se alhear da dimensão de género, passando a reconhecê-la sobretudo num aspeto: as ideologias de masculinidade que marcam a cultura reclusa (Newton, 1994; Sabo et al., 2001). No caso das femininas, contudo, a investigação tem estado em geral inteiramente estruturada pelo género enquanto ângulo analítico que preside a quase todas as questões de investigação: desde a natureza generizada dos regimes prisionais (baseados na feminilidade normativa e na domesticidade, ou mais neutros deste ponto de vista: Bosworth, 1999; Carlen, 1983; Kruttschnitt e Gartner, 2005; Miller e Carbone-Lopez, 2013; McCorkel, 2003), culturas reclusas, socialidades e "dores da reclusão" (postas em relação com papéis e identidades de género, e contrastadas com as versões masculinas: Giallombardo, 1966; Heffernan, 1972; Walker e Worrall, 2000; Ward e Kassebaum, 1965; Zaitzow e Thomas, 2003), a questões de representação (como representar as mulheres, entre vítimas ou dotadas de agencialidade: Fili, 2013).

12 Esta agenda mais "generocêntrica" tem-se tornado apesar de tudo mais diversificada, tanto por razões teóricas como por razões empíricas. Entre elas, o reconhecimento da diversidade intracategoria das experiências e identidades das reclusas; a atenção a uma maior variedade de aspetos da vida prisional além do género, mas também a transformações intra e extramuros; e as variações na saliência real do género como categoria de identidade e vida social nas prisões femininas (Boutron e Constant, 2013; Cunha e Granja, 2014; Greer, 2000; Mandaraka-Sheppard, 1986; Owen, 1998; Rowe, 2011).

\section{0 mundo da instituição}

Passando à questão condutora deste texto - a ligação prisão-sociedade -, refira-se que os estudos contemporâneos de terreno não isolam a abordagem localizada da reclusão penal dos níveis meso ou macro de forças sociais, políticas e legais. Levá-los em conta é desde logo necessário para compreender a demografia inflacionada das atuais populações prisionais, resultante do aumento das taxas de encarceramento na maior parte das democracias liberais desde as últimas décadas do século XX - taxas essas lideradas pelo excecional hiperencarceramento nos EUA4 .

M. Foucault (1977), que não previra este boom prisional e considerava a prisão como um analisador da sociedade, como uma instância condensada de uma racionalidade disciplinar mais ampla, permeando a sociedade num dado período histórico, tinha também identificado uma viragem histórica subsequente: de uma "sociedade disciplinar" para uma "sociedade de segurança" baseada na gestão de riscos (Foucault, 2009). Desde então, vários autores (e.g., Garland, 2001; Feeley e Simon, 1992; Simon, 2007) exploraram esta nova racionalidade, já não apostada em mudar os indivíduos e as suas condições de vida, mas em lidar com eles tal como são ou estão, e em manter afastado o perigo que eventualmente representem. Por outras palavras, uma racionalidade já não baseada na transformação mas na defesa, mais preocupada em avaliar, gerir e prevenir riscos do que 
em corrigir o comportamento de ofensores ou em reintegrar as margens através do Estado-providência.

Embora esta lógica veiculasse uma crítica liberal aos excessos do poder coercivo e da intrusão do poder disciplinar, também se prestou a apropriações pelo populismo penal punitivo, numa crescente cultura de controlo do crime que apela a um tipo de punição puramente retributiva, expressiva e incapacitante, desprovida de fins reabilitadores. De várias maneiras, outros cientistas sociais (e.g., Beckett e Western, 2001; Western, 2006; Harcourt, 2011; Wacquant, 2008, 2009) teorizaram a presente expansão penal principalmente como um resultado do aumento da punição, não do crime. Em vez de analisarem a subida das taxas de encarceramento num estreito quadro criminológico que as ligaria a flutuações nas taxas da criminalidade, articulam-na antes com a desigualdade, as transformações na ação do Estado e a regulação da pobreza pós-industrial.

16 A desregulação do mercado e do trabalho, em conjunto com a retração do Estado social, com políticas sociais impregnadas de lógicas disciplinares, e ainda com uma maior ênfase cultural na responsabilidade individual, convergiram para exacerbar a desigualdade social em vários países e para deteriorar as condições sociais de um precariado urbano, cujos problemas e desordens são depois geridos pelo sistema penal. E se "governar pelo crime" (Simon, 2007) - usando o medo do crime para obter dividendos políticos - se tornou cada mais apelativo nas sociedades pós-industriais, ainda que em graus variáveis, é também porque o Estado reafirma doravante a autoridade pública, debilitada noutras esferas de ação, principalmente através do sistema penal (Wacquant, 2008, 2009). Wacquant considerou por isso a prisão como uma instituição-chave para uma sociologia da regulação da pobreza e para uma antropologia histórica do Estado.

Estas grandes tendências relacionadas entre si refletiram-se ao nível dos próprios regimes prisionais, como o ilustrarão as investigações de terreno mencionadas nesta secção. Contudo, esta investigação também exemplifica que o Estado não deve ser entendido como uma entidade una e singular, com limites precisos e agindo de maneira uniforme e consistente. É antes uma teia diversificada de instituições, procedimentos, racionalidades e atores coexistindo de maneira complexa e por vezes contraditória (Ferguson e Gupta, 2002; Lipsky, 1980). O Estado pode, por seu turno, ser abordado etnograficamente através de uma atenção ao funcionamento concreto das suas instituições, onde políticas e práticas se cruzam e são produzidas na atividade quotidiana dos seus agentes.

As tendências gerais em mutação acima referidas podem de facto ser identificadas nas instituições penais, mas elas não indicam necessariamente uma racionalidade unificada e coerente. Uma atenção às práticas concretas e às rotinas institucionais pode revelar camadas compósitas de diferentes eras penais. Programas prisionais pós-modernos podem coexistir com velhas classificações e disciplinaridades modernistas, lado a lado com modalidades de controlo pré-modernas, tais como revistas corporais, coerção física e elementos neofeudais de punição como deportações e penas de humilhação pública, em variadas versões contemporâneas do pelourinho (Carlen e Tombs, 2006: 356; Shearing, 2001).

Os ideais de reabilitação não desapareceram completamente na viragem punitiva, nem entraram em declínio com a mesma intensidade em todo o lado (Carrier, 2010; Whitman, 2003), mesmo se assumiram novas formas. Algumas das suas reconfigurações fazem-se notar com especial saliência nas prisões de mulheres. P. Carlen e J. Tombs (2006), bem como Kendall e Pollack (2003) e Hanna-Moffat (2001) analisaram algumas implementações institucionais de um atual avatar disciplinar na forma de programas intraprisionais de 
tipo cognitivo-comportamental que, contrariamente à governamentalidade disciplinar clássica, já não emergem confinados ao quadro dos estados-nação, mas emanam de um mercado global de produtos penais descrito como "indústrias de reintegração". Alimentados pelo revivalismo de perspetivas psicologizantes sobre o crime e alheados de quadros sociais profundamente adversos que afetam os/as reclusos/as, estes programas propõem-se reduzir a reincidência, redefinindo os problemas como défices psicológicos que carecem de reajustamentos cognitivos por parte dos/as reclusos/as. Investigação etnográfica recente identificou tendências semelhantes noutro tipo de instituições para o tratamento penal de mulheres (Haney, 2010).

As disciplinaridades podem pois ressurgir nesta remistura de tratamento e punição. Mas técnicas disciplinares anteriores, como o trabalho e a vigilância, perderam também conteúdo disciplinar e ganharam novos sentidos. Mais do que agir sobre as disposições de reclusos/as, induzindo regularidade e autocontrolo, o trabalho prisional pode ser agora encarado por eles/as e por administradores como um direito para assegurar meios de consumo, que se tornou tanto mais importante quanto as populações prisionais se tornaram cada vez mais pobres (Cunha, 2002; Faugeron, 1996; Marchetti, 2002). Mais do que reeditar uma essência panóptica na sua expressão mais refinada, em que a monitorização permanente visava produzir "corpos dóceis", a sofisticação da vigilância tecnológica pode pretender acima de tudo maximizar a segurança (Santoro, 2005). A reclusão "supermax" leva o controlo ao extremo através deste e doutros dispositivos (Rhodes, 2004).

21 Os enfoques na reabilitação e na punição podem também emergir recombinados com, ou transformados por, a ênfase pós-moderna na gestão de riscos, através de uma abordagem gestionária e, tal como outras políticas globalizadas, estandardizada. Nesta linha, noções de "risco como carência social" dão lugar a uma ideia de "risco como perigosidade". Intervenções de reabilitação centradas nas necessidades dos/as prisioneiros/as dão lugar à avaliação e gestão do risco que representam para a segurança pública, assim como à prioridade pós-disciplinar centrada na responsabilidade individual dos/as reclusos/as e na sua livre capacidade de escolha como agentes morais, entendida em termos puramente volitivos (Bosworth, 2007; Hanna-Moffat, 2001).

Esta redefinição da missão da instituição pode ser ilustrada pela deslocação, etnografada em duas prisões francesas por Y. Bouagga (2012), da zona de recrutamento profissional, pelo ethos e pelas práticas dos técnicos prisionais de reinserção, cujo centro de gravidade passou do campo do serviço social para o campo jurídico e criminológico. Bouagga também mostrou que, em lugar de uma intencionalidade sistémica e unitária, o campo prisional é afinal atravessado por posições múltiplas e tendências diferentes, encastradas em relações sociais concretas e no trabalho dos diversos profissionais, exercido dentro de uma variedade de constrangimentos, culturas profissionais, subjetividades e configurações morais. Numa linha semelhante, vários estudos de terreno descreveram as contradições e tensões morais envolvidas nas práticas quotidianas dos agentes institucionais e o modo como novas formas de governamentalidade - tais como o gerencialismo, centrado no desempenho organizacional, em processos mensuráveis, na eficiência administrativa e na eficiência de custos - se combinam com circunstâncias locais para produzir efeitos específicos ao nível da instituição (e.g., Carrabine, 2004; Liebling, 2004; Cheliotis, 2006; Bennet et al., 2008; Crawley, 2004; Chauvenet, 1994).

23 A lógica de prestação de contas e de responsabilidade nas instituições prisionais atuais não se limita, contudo, a uma dimensão económica. Tem também uma dimensão moral. 
Sendo por natureza uma instituição coerciva, a prisão incorre numa suspeita fundamental de ilegitimidade na lógica que preside ao quadro dos direitos humanos, quadro este que estabeleceu limites à punição e que inspira periodicamente reformas prisionais na maior parte das democracias liberais. Expectativas de decência, de respeito pela dignidade e direitos dos/as reclusos/as, de humanização do tratamento penitenciário - também eles parte de uma ética liberal do poder - motivaram a criação de regras e padrões (guidelines e standards) quanto às condições de detenção, direitos e oportunidades básicos dos/as prisioneiros/as. Etnografias e outros estudos de terreno mostraram que, em vez de reduzir de antemão esta tendência a uma mera fachada para mascarar os efeitos deletérios da reclusão e a severidade do tratamento coercivo inspirada pela atual atmosfera política punitiva, é mais produtivo examinar as modalidades concretas em que ela coexiste com forças diferentes dentro da instituição; de que modo ela é implementada ou recua em circunstâncias específicas, e de que modo as garantias formais podem não bastar para assegurar justiça e equidade - podendo mesmo aprofundar a desigualdade estrutural no caso de reclusos/as desprovidos/as dos recursos e do equipamento cultural necessário para "jogar o jogo" nos termos daquilo que a instituição espera que demonstrem, especialmente num meio cada vez mais codificado e burocratizado (e.g., Bouagga, 2012; Crewe, 2009; Cunha, 2002; Liebling, 2004) ${ }^{5}$. Porém, a formalização de uma variedade de procedimentos e interações quotidianos - do controlo à comunicação e aos processos de decisão - modera e contém os excessos do poder institucional na medida em que contribui para minimizar as discriminações flagrantes, e em que confere aos/às reclusos/as alguns meios para contestar a arbitrariedade aberta (Cheliotis, 2006; Easton, 2011).

24 Há pois uma tendência de fundo para a moralização da instituição através da humanização dos regimes prisionais e para uma regulação mais estrita do poder coercivo. Aspetos desta tendência são também conhecidos por "normalização", uma noção que, quando aplicada à prisão, não aos presos, é desprovida das suas conotações foucaultianas e entra no léxico dos responsáveis prisionais em vários países europeus com um significado bem diferente: refere-se à prisão como uma instituição entre outras, logo um subsistema "normal" da sociedade.

As prisões devem, nesta lógica, procurar reduzir o fosso entre o meio interno e externo, e espelhar o meio livre em aspetos indeclináveis da existência humana (de cívicos a sexuais) (Leander, 1995; Snacken, 2002). Esta orientação desafia pois o princípio da "menor elegibilidade", que preconiza ao invés deverem estas instituições manter-se abaixo dos padrões sociais mínimos para poderem permanecer dissuasivas (Easton, 2011; Sieh, 1989). A normalização tem sido implementada em vários graus e formas, em tensão crónica com a "menor elegibilidade" e dentro dos limites variavelmente estabelecidos pelas preocupações de segurança, que tendem a prevalecer quando conflitua com elas nas instituições prisionais.

26 A normalização pode refletir-se em várias práticas, quer ao nível dos/as reclusos/as individuais, considerados na sua identidade pessoal e social, quer ao nível da instituição e dos serviços disponíveis. No primeiro caso, a normalização pode consistir em não substituir identidades prévias pela de recluso/a na forma de um número ou de um uniforme. No segundo, consiste em promover, em vez de reduzir, o acesso à educação, saúde, formação profissional e outros aspetos ainda como visitas íntimas ou direitos de voto (Easton, 2011; Snacken, 2002) ${ }^{6}$. Este acesso apoiado pela instituição não se dá apenas intramuros. A normalização pode assentar numa perspetiva mais ampla sobre a inclusão 
social e a integração de reclusos/as na cidadania, respeitando os seus direitos não apenas como reclusos/as mas também como cidadãos/as plenos/as. Pode assim compreender ações institucionais para promover um acesso a direitos sociais básicos, segurança social e sistema de saúde ${ }^{7}$. Implica também uma integração mais estreita com outros setores da administração pública e uma maior articulação com outras entidades, públicas ou privadas, para a provisão de bens e serviços, que deixa assim de estar organizada separadamente num setor prisional.

Esta maior integração, que tornou os muros da prisão mais permeáveis, inclui ainda os modos de regulação e escrutínio externo que limitam as margens locais de autonomia e o poder discricionário das instituições prisionais. A ordem normativa deslocou-se para níveis superiores, não apenas nacionais mas também transnacionais ou supranacionais ${ }^{8}$. Regimes prisionais, regulamentos e horários não são já inteiramente decididos ao nível dos estabelecimentos prisionais, mas emanam de orientações centralizadas. 0 escrutínio de procedimentos e a supervisão organizacional pelos escalões superiores de autoridades prisionais e não prisionais, a centralização e burocratização dos processos de decisão, a formalização de orientações e a estandardização de procedimentos também deslocaram para cima o locus do poder e da autoridade. Tal resultou num enquadramento mais estreito da ação de funcionários e dirigentes prisionais - refletindo-se, indiretamente, nas próprias configurações sociais reclusas. Dada a reduzida latitude para interpretar e implementar regras prisionais, a administração prisional é menos suscetível de refletir a personalidade e estilo individual dos diretores, mas também se inclina menos para negociar a ordem com estruturas informais paralelas de autoridade de reclusos/as, por exemplo através da cooptação de líderes reclusos na governança institucional. Em vez disso, e em conjunto com a ênfase colocada na responsabilidade individual e na autorregulação do comportamento para a progressão na pena por parte daqueles, a administração prisional contribui para individualizar a comunidade reclusa (Adler e Longhurst, 1994; Barak-Glanz, 1981; Bryan, 2007; Crewe, 2009; Cunha, 2002; Liebling, 2004; Sparks et al., 1996) ${ }^{9}$. Investigações etnográficas em prisões do Sul global parecem indicar porém uma coexistência entre processos de formalização e de informalização na governança institucional (e.g., Barbosa, 2007; Castro e Silva, 2011; Garces, Martin e Darke, 2013).

28 É com base no declínio de regimes institucionais fechados e autoritários, na redução do fosso entre a prisão e a sociedade em termos de padrões e condições de vida e no crescente fluxo de bens, serviços e comunicações (Jewkes, 2002) atravessando os muros da prisão, que a relevância atual do modelo goffmaniano da prisão como "instituição total" (Goffman, 1961) tem sido mais comummente posta em causa (e.g., Chantraine, 2004; Davies, 1989; Lemire e Vacheret, 2007; Farrington, 1992).

\section{A prisão além muros}

29 A investigação de terreno olhou para lá dos muros físicos da prisão ainda de outras formas. Focando o espaço pericarceral da instituição, um tipo de investigação etnográfica examina as trocas com o entorno socioespacial dos estabelecimentos prisionais, em especial como se projetam os efeitos do estigma penal da prisão na vizinhança imediata desta. Um exemplo são os estudos de ecologia social, conduzidos à volta de prisões francesas, mostrando as práticas de relegação social e de distanciação simbólica desenvolvidas no "perímetro sensível" da prisão (Combessie, 2001; Marchetti, 1996; 
Renouard, 1999) e que reforçam a clivagem separando-a do meio livre. Um outro exemplo é a rica etnografia de R. Sabaini (2011), documentando a incorporação social de duas penitenciárias numa cidade do Brasil.

Num registo diferente, outros estudos focaram o perímetro social e relacional da prisão, caracterizando de perto o modo como a reclusão afeta e molda as famílias, parceiros/as e comunidades de proveniência dos/as reclusos/as. Indo para lá dos indivíduos encarcerados e captando além muros a dimensão coletiva da reclusão, estas abordagens tornaram-se tanto mais importantes quanto o aumento das taxas de encarceramento revela uma concentração desproporcionada em minorias étnico-raciais e em comunidades pobres (Wacquant, 2013; Patillo et al., 2004; Western, 2006). Altos níveis de encarceramento concentrado resultaram na ubiquidade da prisão como realidade incrustada no tecido de bairros urbanos pobres, onde a vida das famílias e residentes é atravessada pela presença inescapável do sistema prisional, exaurindo estas comunidades através de vários efeitos específicos, desde sociais e económicos a cívicos e políticos (e.g., Braman, 2004; Clear, 2007; Clear et al., 2001; Cunha, 2008; Patillo et al., 2004). Estudos etnográficos mostraram também o impacto deste encarceramento maciço nas redes de parentesco e vizinhança e nas estruturas informais de apoio e entreajuda (Cunha, 2013).

31 Aproximando mais a lente daqueles que rodeiam os reclusos além muros, um corpo importante de trabalhos de terreno põe em evidência uma "experiência carceral alargada" (Touraut, 2012) que inclui, por um lado, os desafios e dificuldades - financeiras, sociais, emocionais - enfrentadas pelas famílias e parceiros/as de reclusos/as durante a reclusão e, por outro lado, o apoio material, moral e emocional que prestam aos/às reclusos $/ a^{10}$. Abordagens etnográficas em profundidade matizaram a suposição de que a reclusão desorganiza ou desfaz invariavelmente laços interpessoais e mostraram que é demasiado simplista uma análise em termos de meros ganhos e perdas para familiares ou reclusos/as. C. Touraut (2012), em França, e M. Comfort (2008), nos EUA, por exemplo, ilustraram como as experiências podem ser diversas, consoante as circunstâncias interpessoais e socioeconómicas, como as relações através dos muros podem ser ambivalentes e como indivíduos e relações são reconfigurados pela prisão.

Comfort descreveu a "prisionização secundária" de mulheres com parceiros reclusos, um processo de socialização nas normas prisionais e de sujeição ao controlo penal que as induz a depender das autoridades correcionais como a única instituição pública consistente ao seu alcance. $\mathrm{O}$ autor mostrou a coexistência dos efeitos desintegradores e integradores da prisão e descreveu como esta instituição se torna num lugar substituto, distorcido mas gerível, para a vida conjugal e doméstica. Abrigadas de comportamentos violentos e das desordens quotidianas, as mulheres podem ter algum grau de controlo em relações problemáticas. Encontram também alguns ganhos identitários, ao inscreveremse em papéis de género normativos, como o de cuidadora dedicada.

Outras etnografias (e.g., Cunha e Granja, 2014, em Portugal; Palomar Verea, 2007, no México) identificaram um processo de reconfiguração similar no caso de mães reclusas e da sua relação com os filhos. Se é verdade que a separação das crianças pode ser uma fonte constante de stress e gerar sentimentos de se ser uma "má mãe", a prisão também pode dar azo a que as mães aí reelaborem a uma outra luz relações parentais problemáticas. Para mais, em estabelecimentos em que as reclusas podem manter com elas os filhos de tenra idade, este novo meio pode prestar-se a que vivenciem de forma diversa a maternidade, criando novas subjetividades através das quais ressignificam também as suas experiências anteriores de parentalidade: protegidas das pressões 
imediatas da sobrevivência quotidiana, pobreza e violência, com tempo disponível para as crianças - que aqui são também objeto de atenção médico-educativa especializada -, podem experienciar um laço com os filhos com uma intensidade sem precedentes, atribuindo-lhe um sentido que se torna doravante central. Num tal contexto, a maternidade é hiperbolizada nas narrativas da identidade pessoal.

Em ambos os casos apontados - relações conjugais e parentais na sombra da prisão -, estes efeitos menos conhecidos de distorção prisional não deixam de estar relacionados com o facto de a instituição penal se estar a tornar num "serviço social peculiar" e de segunda ordem para gerir problemas não tratados por outros meios e instituições, especialmente num tempo de retração dos Estados Providência (Comfort, 2008).

\section{0 mundo social e subjetivo dos/as reclusos/as}

Mais centrada nos/as reclusos/as, uma rica tradição de etnografia prisional tem explorado o mundo social e subjetivo na prisão, desde as formas culturais, estruturais e de relações sociais, até às formas de poder, adaptação e resistência desenvolvidas no mundo material e moral específico das instituições prisionais.

Estes aspetos têm sido abordados de maneira mais ou menos interrelacionada. As noções de "cultura prisional" e "sociedade reclusa", e a atenção etnográfica ao mundo interno das prisões, tomaram forma na sequência da teoria da prisionização de D. Clemmer (1940), um processo de socialização em valores reclusos que, segundo o autor, seria um obstáculo à reabilitação. G. Sykes (1958) e G. Sykes e S. Messinger (1960) deslocaram o enfoque da prisionização para a cultura em si, um sistema de valores e normas na forma de máximas que definiriam um código de conduta recluso e um conjunto de papéis sociais constatáveis em várias populações prisionais ${ }^{11}$. Teorizaram então a cultura prisional como uma resposta coletiva para obviar a uma série de privações materiais e morais criadas pela situação de reclusão, logo como um mecanismo com origem na prisão em si. Mais tarde, J. Irwin e D. Cressey (1962) defenderiam que, embora a cultura e sociedade reclusa fornecesse meios para lidar com a reclusão, ela não era gerada por propriedades específicas da prisão, sendo em vez disso uma coalescência de subculturas externas importadas para o mundo intramuros.

Desde esta primeira formulação do debate "privação-importação" acerca da base endógena ou exógena da cultura e vida social da prisão, e que continua a reverberar hoje em versões mais ou menos integradas dos dois modelos (e.g., Crewe, 2009; Harvey, 2007; Trammell, 2012), foi pois a comunidade reclusa em si - e não apenas o poder institucional - que deixou gradualmente de ser considerada como um sistema autocontido. Embora nas etapas iniciais ambos os lados do debate convergissem no reconhecimento comum da existência de uma comunidade unificada, estabilizada por uma forma cultural única, quaisquer que fossem as suas origens (cf. Irwin, 1970), a comunidade reclusa passaria mais tarde a ser descrita como fragmentada em fações mutuamente hostis, cada uma com códigos normativos próprios que apenas vinculavam os respetivos membros - fações étnico-raciais, gangues e grupos violentos da economia de rua da droga (e.g., Carroll, 1974; Colvin, 1992; Fleisher, 1989; Irwin, 1980, 2005; Jacobs, 1977).

Condições estruturais - além das culturais - externas tornaram-se assim mais presentes em relatos etnográficos sobre a comunidade reclusa e a sua permeabilidade ao mundo exterior. Ainda assim, os mundos externos integravam estes relatos sobretudo a título de 
background, como contextos prévios que moldavam o mundo moral, as formas culturais reclusas e a estrutura social da prisão. Mas a copresença carceral de membros de gangues e companheiros/as de rua (Carroll, 1974; Días-Cotto, 1996; Fleisher, 1989; Irwin, 1980; Jacobs, 1974; Morris e Morris, 1963), ainda que subteorizada na altura, também indiciava que os muros da prisão já não separavam inteiramente os/as reclusos/as do seu mundo social e que segmentos desse mundo eram também transpostos para a prisão e continuavam a sustentar identidades sociais anteriores (Cunha, 2002).

Mais tarde, fenómenos de encarceramento concentrado observados em vários países, que entrelaçaram instituições carcerais e territórios urbanos economicamente deprimidos e severamente penalizados (e.g., Barbosa, 2006; Biondi, 2010; Clear, 2007; Cunha, 2002, 2010; Wacquant, 2013), questionariam mais ainda as fronteiras da prisão como uma microcena social. A revisitação etnográfica por M. Cunha $(2002,2008)$ de uma prisão de mulheres em Portugal mostrou como a socialidade prisional deixou de ser autorreferencial e se tornou uma extensão de alguns bairros urbanos. O curso desta socialidade passou a ser inseparável da vida quotidiana extramuros através da ramificação de redes que ligam não só as reclusas entre si, mas também a malhas exteriores de relações comuns que cruzam vários círculos dos respetivos parentes, amigos e vizinhos.

Estas constelações transformaram a experiência da reclusão e sincronizaram a temporalidade prisional com os ritmos do mundo exterior. Diversamente da sua anterior etnografia - de tipo "prisão-em-contexto" - na mesma instituição, o autor teve de deslocar o foco etnográfico da prisão para o interface entre o interior e o exterior, a prisão e os bairros, para captar a nova translocalidade da sociedade carceral. Dando a ver, não só a porosidade das fronteiras institucionais, mas também esta outra, mais subterrânea, perpassando o mundo social recluso, este tipo de abordagem traz para um novo patamar o questionamento de narrativas goffmanianas sobre a prisão como "um mundo à parte" (cf. Ainda Crewe, 2009; Bandyopadhyay, 2010).

\section{Conclusões}

41 A relação prisão-sociedade e a articulação entre mundo interno e externo têm sido tratadas com um destaque variável nos estudos prisionais de terreno, a partir de diferentes perspetivas, e atravessando diferentes escalas e quadros analíticos. Numa perspetiva centrada na instituição, a relação das prisões com o mundo além muros foi abordada focando as influências externas refletidas nestas instituições, em especial no exercício institucional do poder coercivo. Transformações mais amplas em racionalidades, governamentalidades e políticas de punição, assim como a deslocação da base normativa e do locus de autoridade para níveis acima das instituições prisionais, repercutiram-se no modo como o poder institucional é exercido - o que por sua vez se reflete nas vivências do encarceramento por parte de reclusos/as. A redução do fosso com a sociedade quanto a padrões e condições de vida e o crescente fluxo de bens, serviços e comunicações que atravessam os muros da prisão foram também objeto de atenção. Esta porosidade institucional nos modos de provisão, regulação e escrutínio põe em causa uma visão do mundo carceral como autárcico, fechado e autossuficiente, ao mesmo tempo que revela a crescente complexidade das modalidades contemporâneas do exercício do poder - uma complexidade onde se inclui a coexistência de práticas e racionalidades contraditórias. 
42 ou meso que moldam o poder institucional e o funcionamento da instituição, a permeabilidade das fronteiras prisionais foi problematizada e documentada etnograficamente ainda de outras maneiras. Outras abordagens da prisão-em-contexto, mas agora centradas na comunidade reclusa, focam esta permeabilidade em termos dos universos externos prévios que moldam identidades, mundos morais, formas culturais e estruturas sociais intramuros.

43

Centradas, quer na vida intramuros de reclusos/as, quer na vida extramuros dos seus familiares, parceiros e comunidades, outras abordagens, a que chamaria de "interface", deslocaram de várias maneiras o enfoque etnográfico para a junção dos dois mundos sociais e iluminaram os seus efeitos recíprocos, ou mesmo a sua constituição mútua em tempos de encarceramento maciço e concentrado que afeta desproporcionalmente categorias específicas de pessoas. No caso dos estudos prisionais de terreno, estas abordagens captam porosidades mais subterrâneas e problematizam as fronteiras das instituições prisionais enquanto cenas microssociais que se tornaram translocais. A interligação a vários níveis dos mundos intra e extramuros levanta assim novas questões metodológicas acerca das fronteiras da prisão enquanto terreno de investigação etnográfica.

Uma maior atenção às relações prisão-sociedade e um crescente reconhecimento da porosidade do que havia antes sido retratado como um universo fechado e circunscrito aos seus limites físicos refletem mudanças macro e micro nas realidades empíricas, mas estão também em sintonia com mudanças em debates teóricos mais amplos, em que os aspetos de fechamento ou, ao invés, de fluxo (Geschiere e Meyer, 1998) são mais ou menos enfatizados. Os estudos prisionais de terreno também incorporaram debates mais vastos ao tornarem-se mais reflexivamente cientes das várias condições da sua própria produção.

\section{BIBLIOGRAPHY}

ADLER, M.; LONGHURST, B. (1994), Discourse, Power and Justice. Towards a new sociology of imprisonment. New York: Routledge.

BANDYOPADHYAY, M. (2010), Everyday Life in an Indian Prison. Confinement, surveillance, resistance. New Delhi: Orient BlackSwan.

BANDYOPADHYAY, M.; JEFFERSON, A.; UGELVIK, T. (2013), "Prison spaces and beyond: the potential of ethnographic zoom”, Criminal Justice Matters, 91 (1): 28-29.

BARAK-GLANZ, I. L. (1981), “Towards a conceptual schema of prison management styles”, Prison J. 61 (2): 42-60.

BARBOSA, A. R. (2006) “O baile e a prisão: onde se juntam as pontas dos segmentos locais que respondem pela dinâmica do tráfico de drogas no Rio de Janeiro”, Especiaria, 9: 119-134. 
BARBOSA, A. R. (2007), “Um levantamento introdutório das práticas de violência física dentro das cadeiras cariocas”, in A. C. Marques (org.), Conflitos, Política e Relações Pessoais. Campinas: Pontes Editora: 129-172.

BECKETT, K.; WESTERN, B. (2001), “Governing social marginality. Welfare, incarceration, and the transformation of state policy", Punishment and Society, 3 (1): 43-59.

BENNETT, J.; CREWE, B.; Wahidin, A. (orgs.), (2008), Understanding Prison Staff. Cullompton: Willan. BIONDI, K. (2010), Junto e Misturado. Uma etnografia do PCC. São Paulo: Editora Terceiro Nome. BOUAGGA, Y. (2012), "Le métier de conseiller d'insertion et de probation: dans les coulisses de l'État pénal”, Sociologie du Travail, 54 (3), 317-337.

BOUTRON, C.; CONSTANT, C. (2013), “Gendering transnational criminality. The case of women's imprisonment in Peru”. Signs, 39 (1): 177-195.

BOSWORTH, M. (1999), Engendering Resistance: Agency and power in women's prisons. Dartmouth: Ashgate.

BOSWORTH, M.; CAMPBELL, D.; DEMBY, B.; FERRANTI, S. M.; SANTOS, M. (2005), “Doing prison research: views from the inside", Qualitative Inquiry, 11: 249-264.

BOSWORTH, M. (2007), “Creating the responsible prisoner. Federal admission and orientation packs", Punishment and Society, 9 (1): 67-85.

BOURDIEU, P.; WACQUANT, L. (2002), "Sobre as artimanhas da razão imperialista”, Estudos AfroAsiáticos, 24 (1): 15-33.

BRAMAN, D. (2004) Doing Time on the Outside: Incarceration and family life in America. Ann Arbor: University of Michigan Press.

BRYAN, S. (2007), Managing Prisons in a Time of Change. Cullompton: Willan.

CARLEN, P. (1983), Women's Imprisonment: A study in social control. London: Routledge and Kegan Paul.

CARLEN, P.; TOMBS, J. (2006) "Reconfi gurations of penality. The ongoing case of the women's imprisonment and reintegration industries", Theoretical Criminology, 10 (13): 337-360.

CARRIER, N. (2010), “Sociologies anglo-saxonnes du virage punitive”. Champ pénal / Penal field, Nouvelle revue internationale de criminologie, VII (23), http://champpenal.revues.org/7818.

CARROLL, L. (1974), Hacks, Blacks and Cons. Race relations in a maximum security prison. Illinois: Waveland Press.

CASTRO e SILVA A. M. (2011), Participo que... Desvelando a Punição Intramuros. Rio de Janeiro: Publit.

CHANTRAINE, G. (2004), Par-delà les murs. Expériences et trajectoires en maison d'arrêt. Paris: PUF.

CHANTRAINE, G. (2013), "Prisons under the lens of ethnographic criticism", Criminal Justice Matters, 91 (1): 30-31.

CHAUVENET, A.; ORLIC, F. (1994), Le Monde des surveillants de prison. Paris: PUF.

CHELIOTIS, L. (2006), "How iron is the iron cage of new penology? The role of human agency in the implementation of criminal justice policy", Punishment and Society 8 (3): 313-340.

CLEAR, T. R. (2007), Imprisoning Communities. How mass incarceration makes disadvantaged neighborhoods worse. New York: Oxford University Press. 
CLEAR, T.; ROSE, D. R.; RYDER, J. A. (2001), "Incarceration and community: the problem of removing and returning offenders", Crime and Delinquency, 47 (3), 335-351.

CLEMMER, D. (1940), The Prison Community. New York: Rinehart e Co.

COHEN, S.; TAYLOR, L. (1972), Psychological Survival: The experience of long-term imprisonment. Harmondsworth: Penguin Books.

COLVIN, M. (1992), The Penitentiary in Crisis. Accommodation to riot in New Mexico. New York: State University of New York Press.

COMBESSIE, P. (2002), "Marking the carceral boundary. Penal stigma in the long shadow of the prison”, Ethnography, 3(4): 535-555.

COMFORT, M. L. (2008), Doing Time Together: Forging love and family in the shadow of the prison. Chicago: Chicago University Press.

CRAWLEY, E. (2004), Doing Prison Work. The public and private lives of prison officers. Cullompton: Willan.

CREWE, B. (2009), The Prisoner Society: Power, adaptation, and social life in an English prison. Oxford: Oxford University Press.

CREWE, B.; MARUNA, S. (2006), "Self-narratives and ethnographic fi eldwork”, in D. Hobbs, R. Wright (orgs.), The Handbook of Fieldwork. London: Thousand Oaks CA, Sage, 109-124.

CUNHA, M. (1994), Malhas que a Reclusão Tece. Questões de identidade numa prisão feminina. Lisboa: CEJ.

CUNHA, M. (2002), Entre o Bairro e a Prisão: Tráfi co e trajectos. Lisboa: Fim de Século.

CUNHA, M. (2008), “Closed circuits: kinship, neighborhood and imprisonment in urban Portugal”, Ethnography, 9 (3): 325-350.

CUNHA, M. (2010), "Race, crime and criminal justice in Portugal", in A. Kalunta-Crumpton (org.), Race, Crime and Criminal Justice: International perspectives. New York: Palgrave MacMillan, 144-61.

CUNHA, M. (2013), "The changing scale of imprisonment and the transformation of care: the erosion of the 'welfare society' by the 'penal state' in contemporary Portugal”, in M. Schlecker, F. Fleischer (orgs.), Ethnographies of Social Support. New York: Palgrave MacMillan, 81-101.

CUNHA, M.; GRANJA, R. (2014, no prelo), "Gender asymmetries, parenthood and confi nement in two Portuguese prisons", Champ Pénal/Penal Field.

DAVIES, C. (1989) “Goffman's concept of the total institution: criticism and revisions”, Human Studies, 12: 77-95.

DAVIES, P. (2000), "Doing interviews with female offenders", in V. Jupp, P. Davies, P. Francis (orgs.) Doing Criminological Research. Thousand Oaks, CA, Sage: 82-96.

DÍAZ-COTTO, J. (1996), Gender, Ethnicity and the State. Latina and Latino prison politics. New York: State University of New York Press.

EASTON, S. (2011), Prisoners' Rights: Principles and practice. S. Easton, London: Routledge.

FARRINGTON, K. (1992), “The modern prison as total institution? Public perception versus objective reality". Crime and Delinquency, 38 (1): 6-26.

FAUGERON, C. (1996), "The changing functions of imprisonment”, in R. Mathews, P. Francis (orgs.), Prisons 2000. An international perspective on the current state and future of imprisonment. London: McMillan Press: 121-138. 
FEELEY, M.; SIMON, J. (1992), “The new penology: notes on the emerging strategy of corrections and its implications", Criminology, 30 (4): 449-474.

FERGUSON, J.; GUPTA, A. (2002), “Spatializing states: toward an ethnography of neoliberal governmentality”, American Ethnologist, 29 (2): 981-1002.

FILI, A. (2013), “Women in prison: victims or resisters. Representations of agency in women's prisons in Greece”, Signs, 39 (1): 1-26.

FLEISHER, M. S. (1989), Warehousing Violence. California: Sage Publications.

FOUCAULT, M. (1977), Discipline and Punish: The birth of the prison. Trans. Sheridan A. London: Penguin.

FOUCAULT, M. (2009), Security, Territory, Population: Lectures at the College de France 1977-1978. New York: Picador.

GARCES, C.; MARTIN, T.; DARKE, S. (2013), "Informal prison dynamics in Africa and Latin America”, Criminal Justice Matters, 91 (1): 26-26.

GARLAND, D. (2001), The Culture of Control. Crime and social order in contemporary society. Oxford University Press.

GENDERS, E.; PLAYERS, E. (1989), Race Relations in Prison. Oxford: Oxford University Press.

GENDERS, E.; PLAYERS, E. (2010), “Revisiting Grendon 20 years on”, The Howard J. 49 (5): 431-450.

GESCHIERE, P.; MEYER, B. (1998), Globalization and Identity: Dialectics of $f l$ ow and closure. Oxford: Blackwell.

GIALLOMBARDO, R. (1966), Society of Women. A study of a women's prison. New York: John Wiley e Sons.

GOFFMAN, E. (1961), Asylums: Essays on the Social Situation of Mental Patients and Other Inmates. Harmondsworth: Penguin.

GREER, K. (2000), “The changing nature of interpersonal relationships in a women's prison”, Prison J. 80 (4): 442-468.

HANEY, L. A. (2010), Offending Women: Power, punishment, and the regulation of desire. Berkeley: University of California Press. Loïc Wacquant

HANNA-MOFFAT, K. (2001), Punishment in Disguise. Governance and federal imprisonment of women in Canada. Toronto: University of Toronto Press.

HARCOURT, B. E. (2011), The Illusion of Free Markets: Punishment and the myth of natural order. 1 vol. Cambridge, Mass: Harvard University Press.

HARVEY, J. (2007), Young Men in Prison. Surviving and adapting to life inside. Cullompton: Willan.

HEFFERNAN, E. (1972), Making It in Prison. The square, the cool and the life. New York: John Wiley and Sons.

IRWIN, J. (1970), The Felon. New Jersey: Prentice-Hall.

IRWIN, J. (1980), Prisons in Turmoil. Boston: Little, Brown and Company.

IRWIN, J. (1985), The Jail. Berkeley CA: University of California Press.

IRWIN, J. (2005), The Warehouse Prison. Disposing of the new dangerous classes. Los Angeles: Roxbury. IRWIN, J.; CRESSEY, D. (1962), "Thieves, convicts and the inmate culture”, Social Problems, 10: 142-155. 
JACOBS, J. (1974), “Street gangs behind bars”, Social Problems, 21 (3): 395-409.

JACOBS, J. (1977), Stateville. The penitentiary in mass society. Chicago: University of Chicago Press.

JENNESS, V. (2010), “From policy to prisoners to people: a soft mixed methods approach to studying transgender prisoners", Journal of Contemporary Ethnography, 39 (5): 517-553.

JEWKES, Y. (2002), Captive Audience. Media, masculinity and power in prisons. Cullompton: Willan.

JEWKES, Y. (2012), “Autoethnography and emotion as intellectual resources: Doing prison research differently”, Qualitative Inquiry, (1) 18: 63-75.

KAMINSKI, M. (2004), Games Prisoners Play. The tragicomic worlds of Polish prison. Princeton NJ: Princeton University Press.

KENDALL, K.; POLLACK, S. (2003) “Cognitive behaviouralism in women's prisons: a critical analysis of therapeutic assumptions and practices", in B. Bloom (org.), Gendered Justice. Addressing female offenders. Durham NC: Carolina Academic Press, 69-96.

KHOSROKHAVAR, F. (2004), L'Islam dans les prisons. Paris: Éditions Balland.

KING, R. (2007), “Imprisonment: Some international comparisons and the need to revisit panopticism", in Y. Jewkes (ed.), Handbook on Prisons. New York: Willan Publishing.

KING, R.; WINCUP, E. (orgs.) (2000), Doing Research on Crime and Justice. Oxford: Oxford University Press.

KRUTTSCHNITT, C.; GARTNER, R. (2005), Marking Time in the Golden State: Women's imprisonment in California. Cambridge: Cambridge University Press.

LEANDER, K. (1995), “The normalization of Swedish prisons”, in V. Ruggiero, M. Ryan, J. Sim

(orgs.), Western European Penal Systems. A critical anatomy. London: Sage, 167-193.

LE CAISNE, L. (2000), Prison. Une ethnologue en centrale. Paris: Editions Odile Jacob.

LEMIRE, G.; VACHERET, M. (2007), Anatomie de la prison contemporaine. Montréal: Presses de l'Université de Montréal.

LIEBLING, A. (2001), "Whose side are we on? Theory, practice and allegiances in prison research", British Journal of Criminology, 41: 472-484.

LIEBLING, A. (2013), "Identity and emotion in a high security prison", Criminal Justice Matters, 91 (1): 22-23.

LIEBLING, A.; ARNOLD, H. (2004), Prisons and Their Moral Performance. A study of values, quality and prison life. Oxford: Clarendon Press.

LIPSKY, M. (1980), Street-Level Bureaucracy: Dilemmas of the individual in public services. Nova Iorque: Russel Sage Foundation.

MANDARAKA-SHEPPARD, A. (1986), The Dynamics of Agression in Women's Prisons in England. London: Gower.

MARQUART, J. W. (1986), "Doing research in prison: the strengths and weaknesses of full participation as a guard", Justice Quarterly, 3(1): 15-32.

MARCHETTI, A.; COMBESSIE, P. (1996), La Prison dans la cité. Paris: Desclée de Brouwer.

MARCHETTI, A. (2002) "Carceral impoverishment. Class inequality in the French penitentiary", Ethnography, 3(4): 416-434. 
MATHIESEN, T. (1965) The Defences of the Weak. A sociological study of a Norwegian correctional institution. London: Tavistock.

McCORKELL, J. A. (2003), "Embodied surveillance and the gendering of punishment", Journal of Contemporary Ethnography, 32 (1): 41-76.

MELE, C.; MILLER, T. A. (orgs.) (2005), Civil Penalties, Social Consequences. New York: Routledge. MILLER, J.; CARBONE-LOPEZ, K. (2013), “Gendered carceral regimes in Sri-Lanka: colonial laws, post-colonial practices and the social control of sex workers", Signs, 39 (1): 79-103.

MILLS, A.; CODD, H. (2007), “Prisoner's' Families”, in Y. Jewkes (ed.), Handbook on Prisons. New York: Willan Publishing, 672-695.

MORRIS, P.; MORRIS T. (1963), Pentonville. A sociological study of an English prison. London: Routledge.

NEWTON, C. (1994), "Gender theory and prison sociology: using theories of masculinities to interpret the sociology of prisons for men", The Howard Journal of Criminal Justice, 33: 193-202.

NIELSEN, M. M. (2010), "Pains and possibilities in prison: on the use of emotions and positioning in ethnographic research", Acta Sociologica, 53(4): 307-321.

OWEN, B. (1998), In the Mix: Struggle and survival in a women's prison. Albany, NY: State University of New York Press.

PALOMAR VEREA, C. (2007) Maternidad en Prisión. Guadalajara: Universidad de Guadalajara.

PATILLO, M.; WEIMAN, D.; WESTERN, B. (eds.), (2004), Imprisoning America: The social effects of mass incarceration. New York: Russel Sage Foundation Press.

PHILLIPS, C.; EARLE, R. (2010), "Reading difference differently? Identity, epistemology and prison ethnography", British Journal of Criminology, 50 (2): 360-378.

PIACENTINI, L. (2004), Punishment, Economy and Politics in Transition. Cullompton: Willan Publishing.

PIACENTINI, L. (2007), "Researching Russian prisons: a consideration of new and established methodologies in prison research", in Y. Jewkes (ed.), Handbook on Prisons. New York: Willan.

PRATT, J. (2002), Punishment and Civilization. Penal tolerance and intolerance in modern society. London: Sage.

REED, A. (2004), Papua New Guinea's Last Place. Experiences of constraint in a postcolonial prison. Oxford/New York: Berghan Books.

RENOUARD, J. (1990), “La prison de l'île de Ré: un travail d'équipe”, Questions pénales, 12 (4): 1-4.

RHODES, L. (2001), “Toward an anthropology of prisons”, Annual Reviews of Anthropology, 30: 65-87.

RHODES, L. (2004), Total Confinement: Madness and reason in the maximum security prison. Berkeley/ Los Angeles/London: University of California Press.

RIBEIRO G. L.; ESCOBAR, A. (orgs) (2006), World Anthropologies: Disciplinary transformations within systems of power. Oxford/New York: Berg.

ROWE, A. (2011), “Narratives of self and identity in women's prisons: stigma and the struggle for self-definition in penal regimes", Punishment and Society, 13: 571-591.

RUGGIERO, V.; RYAN, M.; SIM, J. (orgs.) (1996), Western European Penal Systems. A critical anatomy. London: Sage. 
SABAINI, R. (2011), “Uma cidade entre presídios: percepções acerca de um contínuo entre a prisão e o urbano", Sociedade e Território, Natal, 23 (2): 21-37.

SABO, D.; KUPERS, T. A.; LONDON, W. (orgs.) (2001), Prison Masculinities. Philadelphia, PA: Temple University Press.

SANTORO, E. (2005), “Modalità punitive e strutture della soggettività. Il carcere democratico: una lettura foucaultiana delle nuove politiche penali”, in A. Petrillo (org.), Un lavoro disperso e mutevole: la cartografi a sociale di Michel Foucault. Avelino: Sellino Editore.

SHEARING, C. (2001), "Punishment and the changing face of governance", Punishment and Society, 3(2): 203-220.

SIEH, E. W. (1989), "Less eligibility: The upper limits of penal policy", Criminal Justice Policy Review, 3 (2): 159-183.

SIMON, J. (2007), Governing through Crime. New York: New York University Press.

SLOAN J.; DRAKE D. H. (2013), "Emotional engagements: On sinking and swimming in prison research and ethnography”, Criminal Justice Matters, 91 (1): 24-25.

SNACKEN, S. (2002), “'Normalisation' dans les prisons: concept et défi s. L'exemple de l'avantproject de loi pénitentiaire belge”, in O. Schutter; D. Kaminski (orgs.) L'Institution du droit pénitentiaire - Enjeux de la reconnaissance de droits aux détenus. La pensée juridique, Bruylant L. G. D. $\mathrm{J}$.

SNACKEN, S.; VAN ZYL SMIT, D. (2009), Principles of European Prison Law and Policy: Penology and human rights. Oxford: Oxford University Press.

SPARKS, R. (2002), “Out of the 'Digger': The warrior's honour and the guilty observer”, Ethnography, 3: 556-581.

SPARKS, R.; BOTTOMS, A.; HAY, W. (1996), Prisons and the Problem of Order. Oxford: Clarendon Press.

SPEDDING, A. L. (1999), "Dreams of leaving. Life in the feminine penitentiary center", Miraflores, La Paz, Bolivia, Anthropology Today, 15 (2): 11-17.

SUTTON, J. E. (2011), “An ethnographic account of doing survey research in prison: Descriptions, reflections, and suggestions from the fi eld", Qualitative Sociology Review, VII (2): 45-63.

SYKES, G. (1958), The Society of Captives. A study of a maximum security prison. Princeton: Princeton University Press.

SYKES, G.; MESSINGER, S. (1960), “The inmate social system”, in R. Cloward et al., Theoretical Studies in Social Organization of the Prison. New York: Social Research Council, 5-19.

TONRY, M. (2004), Thinking about Crime. Sense and sensibility in American penal culture. New York: Oxford University Press.

TONRY, M. (org.) (2007), Crime, Punishment and Politics in Comparative Perspective. Chicago, IL: University of Chicago Press.

TOURAUT, C. (2012), La Famille à l'épreuve de la prison. Paris: PUF.

TRAMMELL, R. (2012), Enforcing the Convict Code: Violence and prison culture. Boulder, CO/ London: Lynne Rienner.

TRAVIS, J.; WAUL, M. (orgs.) (2003), Prisoners once Removed: The impact of incarceration and reentry on children, families and communities. Washington, DC: Urban Institute Press. 
UGGER, C.; MANZE, J. (2004) "Lost voices: The civic and political views of disenfranchised felons", in Mary Patillo et al. (orgs.). Imprisoning America: The social effects of mass incarceration. New York: Russel Sage Foundation Press, 165-204.

UGELVIK, T. (2012), "Prisoners and their victims: Techniques of neutralization, techniques of the self”, Ethnography. 1(13): 259-277.

VAKHOVINE, Y. (2004), “The (post)-Soviet prison subculture faced with the use of selfmanagement doctrines by the corrections administration", Champ Pénal/Penal Field. I. http:// champpenal.revues.org/399.

WACQUANT, L. (2002), "The curious eclipse of prison ethnography in the age of mass incarceration”, Ethnography 3(4): 371-397.

WACQUANT, L. (2008), Urban Outcasts: A comparative sociology of advanced marginality. Cambridge, UK: Polity Press.

WACQUANT, L. (2009) Punishing the Poor. Durham, NC: Duke University Press.

WACQUANT, L. (2013), Deadly Symbiosis: Race and the rise of the penal state. Cambridge, UK: Polity Press.

WALDRAM, J. B. (2009), “Challenges of prison ethnography”, Anthropology News, 50(1): 4-5.

WALKER, S.; Worrall, A. (2000), "Life as a woman. The gendered pains of indeterminate imprisonment”, Prison Service Journal, 132: 27-37.

WALMSLEY, R. (2011), World Prison Population List. Essex: International Center for Prison Studies. 9th ed.

WARD, D.; KASSEBAUM, G. (1965), Women's Prison: Sex and social structure. Chic ago: Aldine.

WESTERN, B. (2006), Punishment and Inequality in America. New York: Russell Sage.

WHITMAN, J. Q. (2003), Harsh Justice: Criminal punishment and the widening divide between America and Europe. New York: Oxford University Press.

ZAITZOW, B.; Thomas, T. (orgs.) (2003), Women in Prison: Gender and social control. Boulder CO: Lynn Rienner Publishers.

\section{NOTES}

1. Num outro registo, ver também Rhodes (2001).

2. Para experiências de participação de reclusos na investigação, ver Bosworth et al. (2005).

3. Esta cautela é tanto mais necessária quanto a penalização acrescida de pessoas percebidas como "outras" afeta cada vez mais a paisagem prisional em diferentes continentes (Wacquant, 2013.)

4. Cf. Walmsley (2011). Sendo uma tendência geral, há contudo diferenças entre os EUA e a Europa nas culturas penais e no uso da reclusão (Pratt, 2002; Tonry, 2004, 2007).

5. Num paralelismo mais amplo a estas coexistências intrainstitucionais entre tendências aparentemente opostas, M. Gottschalk (2006) mostrou como a severidade da punição e a viragem punitiva que resultaram no hiperencarceramento nos EUA ocorreram na sequência de reformas prisionais destinadas a melhorar os direitos dos reclusos.

6. Ao contrário dos EUA (Mele e Miller, 2005), a maior parte dos países europeus e outras democracias não destitui os condenados de direitos cívicos e políticos. Os prisioneiros continuam a participar no sistema político através do exercício do direito de voto. 
7. Ver por exemplo processos de normalização em prisões francesas através da formulação "fazer entrar [os reclusos] no direito comum" (Bouagga, 2012, nt).

8. Ver as Regras Penitenciárias Europeias que desde 1987 fixaram orientações formais para as administrações penitenciárias dos países-membros do Conselho da Europa, e a ação do Tribunal Europeu dos Direitos Humanos (Snacken e Van Zyl Smit, 2009).

9. Este tipo de interação de estruturas formais e informais de autoridade tende a ocorrer sobretudo num modelo de gestão autoritário e discricionário. Dois dos modelos de gestão prisional identificados por I. Barak-Glanz (1981) nos EUA são também relevantes na história das instituições penais europeias: o "modelo autoritário" e o "modelo burocrático-legal" (ver também Vakhovine, 2004, para as antigas repúblicas soviéticas). Este último modelo tendeu gradualmente a prevalecer em ambos os lados do Atlântico. Etnografias prisionais mostraram como esta evolução moldou profundamente a vida prisional contemporânea a níveis diferentes e interrelacionados (e.g., Crewe, 2009; Cunha, 2002).

10. Para uma perspetiva geral, ver Mills e Codd (2007), Patillo et al. (2004), Travis e Waul (2003).

11. Apesar desta recorrência, relatos etnográficos no mesmo período mostraram uma paisagem cultural intraprisional menos uniforme (ver adiante estudos sobre prisões femininas e a etnografia de Mathiesen (1965) sobre uma prisão norueguesa).

\section{ABSTRACTS}

Este artigo traça o panorama atual da investigação de terreno sobre a reclusão penal, identificando linhas de evolução e caracterizando-as em relação a temas-chave e debates clássicos. Procurando internacionalizar mais esta discussão através de um alargamento do habitual enfoque nos EUA e no mundo anglófono, o texto organiza-se em torno de uma questão: a ligação prisão-sociedade e a articulação entre o mundo intra e extramuros. Esta articulação é focada a partir de várias perspetivas e escalas de análise, ora mais centradas na instituição e no seu funcionamento, ora nos/as prisioneiros/as e no seu mundo social, dentro e fora da prisão. A porosidade das fronteiras prisionais também foi problematizada e etnografada de diferentes maneiras, entre abordagens da "prisão-em-contexto" e abordagens de "interface", ambas agora mais reflexivas e entrosadas com debates teóricos mais amplos.

This article maps out the main current developments of field research on prisons and characterises them in relation to key themes that shaped earlier approaches. Internationalising the ethnographic discussion by broadening the predominant focus on the US and the Englishspeaking world, the paper is organised around a main line of discussion: the "prison-society" relation and the articulation between intramural and extramural worlds. This articulation is addressed from different perspectives - within and across different scales and analytic frames -, whether more cantered on the workings of the institution, or on prisoners and their social world, both within and outsider walls. The porosity of prison boundaries has also been problematised and ethnographically documented in different ways: from "prison-in-context" approaches to "interface" approaches, both now more reflexive and attuned to broader theoretical debates.

Les principaux développements actuels de la recherche de terrain sur les prisons sont décrits et caractérisés relativement aux thèmes-clés qui marquèrent les approches plus anciennes. En internationalisant la discussion ethnographique grâce à un élargissement de la focalisation qui 
prédomine sur les États-Unis et le monde anglophone, il est possible d'organiser la discussion autour d'une ligne principale d'analyse : la relation « prison-société » et l'articulation entre les mondes intra- et extra-muros. Cette articulation est abordée depuis différentes perspectives inclues dans et transversales à différents cadres et échelles d'analyse -, centrées soit plutôt sur le fonctionnement de l'institution soit sur les prisonniers et leur monde social, à la fois à l'intérieur et à l'extérieur des murs. La porosité des limites de la prison a aussi été problématisée et documentée ethnographiquement de différentes manières : des approches « prison-en-contexte " à celles du type " interface ", toutes deux désormais plus réflexives et attentives à des débats théoriques plus larges.

INDEX

Mots-clés: Prison, ethnographie, prison et société, culture carcérale, expérience carcérale Keywords: Prison ethnography, prison and society, prison boundaries, prison culture, prison experience.

Palavras-chave: Etnografia prisional, prisão e sociedade, cultura prisional, experiência prisional

\section{AUTHOR}

\section{MANUELA IVONE CUNHA}

CRIA-UMinho, Universidade do Minho, IDEMEC, Endereço de correspondência: Instituto de Ciências Sociais da Universidade do Minho, Campus de Gualtar, 4710-057 Braga, Portugal micunha@ics.uminho.pt 